\title{
Adaptive Changes of Sugar Absorption in Rat Small Intestine during Fasting and Refeeding
}

\author{
Kazuhiko Yamada, ${ }^{1}$ Hisae Shinohara, ${ }^{1}$ Rie Hyodo, ${ }^{2}$ Fusako Soneda, ${ }^{2}$ \\ Michiko SugiYama, ${ }^{2}$ Sachiko Moriuchi, ${ }^{2}$ Naoko Yamada, ${ }^{2}$ \\ Masako OsumI, ${ }^{2}$ and Norimasa Hosoya, ${ }^{1, *}$ \\ ${ }^{1}$ Department of Nutrition, School of Health Sciences, Faculty of Medicine, \\ The University of Tokyo, Hongo, Tokyo 113, Japan \\ ${ }^{2}$ School of Home Economics, Japan Women's University, \\ Mejirodai, Tokyo 112, Japan
}

(Received December 16, 1985)

Summary The effects of fasting and refeeding on the adaptive changes in intestinal sugar absorption was observed by measuring the transmural potential difference $(\triangle \mathrm{PD})$ evoked by glucose by infusion of sugars and compared with those in disaccharidase activities, glucose uptake and phlorizin binding activity to the brush border membranes, and morphological parameters.

Rats were fasted for 1,3 , or 5 days. The rats fasted for 5 days were refed for 1 or 3 days further. The $\Delta \mathrm{PD}$ evoked by glucose, maltose, or sucrose in everted jejunal segments decreased within 1 day of fasting, remained at a same level during fasting, and then increased to the control level after refeeding. Maltase and sucrase activities did not change during the first day of fasting, but did so significantly after 3 days of fasting, in terms of both specific and total activities. On refeeding, disaccharidase activities increased rapidly. However, in spite of significant changes in $\triangle \mathrm{PDs}$ and disaccharidase activities, glucose uptake by and phlorizin-binding to brush border membrane vesicles from jejunal mucosa did not change in either 5 day-fasted or refed animals compared with the control group. On the other hand, jejunal villus height in rats fasted for 5 days decreased significantly compared with that in control rats and was accompanied by a reduction in epithelial cell height and surface area of villi.

These results suggest that the absorption of sugar in small intestine could adapt to fasting and refeeding with changes in disaccharidase activity and surface area, without any change in glucose carrier.

Key Words: disaccharidase, small intestine, sugar absorption, phlorizin binding, brush border membrane

*To whom correspondence should be addressed. 
Because of recent trends in popular use of intravenous alimentation in clinical nutrition, it is important to clarify the effect of luminal factors on the regulation of adaptive changes in intestinal absorption.

Many studies have shown that rapid alterations in mucosal functions are observed in response to the composition of diet [1], fasting [2], total parenteral nutrition [3], intestinal resection [4], or diabetes mellitus [5,6]. However, the mechanisms regulating the adaptation of intestinal absorption are incompletely understood. Especially, the observations on the effects of fasting are contradictory, i.e., fasting has been reported to increase $[7,8]$ or decrease $[9,10]$ the absorption of sugars and amino acids.

Glucose is generally accepted to be actively absorbed via carrier-mediated steps by the intestinal brush border membrane. A net mucosal-serosal flux of glucose is accompanied with that of $\mathrm{Na}^{+}$, which induces a transmural potential difference (4PD) [11]. Recently, it was reported that phlorizin binds specifically to the $\mathrm{Na}^{+}$glucose cotransporter in the intestinal brush border membrane [12].

Therefore, we investigated the effects of fasting and refeeding on the adaptive changes in intestinal sugar absorption by measuring the $\triangle \mathrm{PD}$ evoked by infusion of various sugars and comparing it with disaccharidase activities, glucose uptake, and phlorizin-binding activity to the brush border membrane vesicles, as well as with morphological parameters such as length of microvilli, absorptive surface area, etc.

\section{MATERIALS AND METHODS}

Animals. Male rats of the Wistar strain, weighing about $250 \mathrm{~g}$, were kept at constant temperature $\left(23 \pm 1^{\circ} \mathrm{C}\right)$ and given a standard laboratory chow (Oriental Yeast Co.) and water ad libitum for a week before the initiation of the experiment. Then, the rats were fasted for 1, 3, or 5 days. The rats fasted for 5 days were refed a laboratory chow for 1 or 3 days further. Control rats were fed ad libitum. During the experiments, all rats had unrestricted access to water. The rats were killed by decapitation between 9:00 and 10:30. Blood glucose concentrations were tested by the glucose oxidase method of Dahlqvist [13].

Preparation of isolated intestinal segments. The small intestine from the ligament of Treitz to the ileocecal junciton was quickly removed. The jejunal segment ( $3 \mathrm{~cm}$ in length) was taken out from the intestine beginning approx. 10 to $13 \mathrm{~cm}$ from the ligament of Treitz, rinsed with a standard buffer solution (composition described below), everted, and fixed over a small fenestrated polyethylene tube (5 $\mathrm{mm}$ outer diameter). Thereafter, each everted segment was tied at both ends with cotton threads over the tube [14]. The inside of the tube was filled with the standard solution and the mucosal side of the intestine was exposed to $9 \mathrm{ml}$ of bathing solution (standard solution). The bathing solution was continuously aerated during experiments and its temperature was kept constant at $37^{\circ} \mathrm{C}$. The standard solution 
had the following composition (in $\mathrm{mM}$ ): $\mathrm{Na}_{2} \mathrm{SO}_{4}, 50$; mannitol, $160 ; \mathrm{CaSO}_{4}, 1.5$; $\mathrm{MgSO}_{4}, 1.0 ; \mathrm{KH}_{2} \mathrm{PO}_{4}, 0.5 ; \mathrm{K}_{2} \mathrm{HPO}_{4}, 2.0$ (pH 7.4).

Recording of transport-related increments in the transmural potential. $\triangle \mathrm{PD}$ was led out by connecting calomel half cells to the mucosal and serosal media by means of $2 \%$ agar containing $3 \mathrm{M} \mathrm{KCl}$ and was recorded by a high-sensitivity DC penrecorder (National VP 6541A). The polarity of the electrode in contact with the mucosal medium was negative with respect to that in contact with the serosal medium. After the spontaneous $\triangle \mathrm{PD}$ had attained a steady level, a certain small amount of sugar, dissolved in $1 \mathrm{ml}$ of standard solution, was rapidly injected into the mucosal medium $(9 \mathrm{ml})$. The final concentration of sugar was $20 \mathrm{~mm}$ for Dglucose, $10 \mathrm{~mm}$ for maltose, or $40 \mathrm{~mm}$ for sucrose.

Preparation of brush border membrane vesicles. Jejunal mucosa was scraped by a glass slide from the proximal half of the small intestinal segment. Brush border membrane vesicles were prepared from the jejunal mucosa according to the method of Toggenburger et al. [12]. Mucosal scrapings were suspended in $25 \mathrm{vol}$ of icecold $50 \mathrm{~mm}$ mannitol in $2 \mathrm{~mm}$ Tris- $\mathrm{HCl}$ buffer $(\mathrm{pH} 7.1)$ and homogenized using a Polytron (Brinkman Instruments) for $1 \mathrm{~min}$. Calcium chloride was added to the homogenate to give a final concentration of $10 \mathrm{~mm}$. After being kept in the cold for $20 \mathrm{~min}$, the suspension was centrifuged at $3,000 \times g$ for $15 \mathrm{~min}$, and the resulting supernatant was centrifuged at $27,000 \times g$ for $30 \mathrm{~min}$. The pellet was then resuspended in $2 \mathrm{vol}$ of $100 \mathrm{~mm}$ mannitol in $10 \mathrm{~mm}$ Tris-HEPES (N-2-hydroxyethylpiperazine- $\mathrm{N}^{\prime}$-2-ethanesulfonic acid) buffer ( $\mathrm{pH}$ 7.5) and centrifuged once more at $27,000 \times g$ for $30 \mathrm{~min}$. The pellets, which contained almost pure brush border membrane vesicles, were resuspended in $100 \mathrm{~mm}$ mannitol in $10 \mathrm{~mm}$ TrisHEPES buffer ( $\mathrm{pH} 7.5$ ). The suspended vesicles contained about 6-8 mg protein per ml.

Measurement of glucose uptake and phlorizin-binding activity to brush border membrane vesicles. Uptake of glucose and phlorizin binding to brush border membrane vesicles were determined by the nitrocellulose membrane filtration technique described by Hopfer et al. [15] and by Klip et al. [16]. They were both measured at room temperature (ca. $22^{\circ} \mathrm{C}$ ). Twenty microliters of vesicles were carefully placed in the bottom of a clear polystyrene test tube. The same volume of $2.0 \mathrm{~mm}\left[{ }^{3} \mathrm{H}\right] \mathrm{glu}-$ cose or $10 \mu \mathrm{M}\left[{ }^{3} \mathrm{H}\right]$ phlorizin containing $100 \mathrm{~mm}$ mannitol, $10 \mathrm{~mm}$ Tris-HEPES, and $100 \mathrm{~mm}$ NaSCN or KSCN was placed as a separate drop at the bottom of the tube. The uptake or binding was started by rapid mixing using a vortex and terminated after $15 \mathrm{~s}$ by dilution with $2.5 \mathrm{ml}$ of ice-cold $1 \mathrm{mM}$ Tris- $\mathrm{HCl}$ buffer (pH 7.0) containing $250 \mathrm{~mm} \mathrm{NaCl}$. The diluted sample was immediately transferred onto a nitrocellulose filter $(0.45 \mu \mathrm{m}$ pore size, Schleicher Schuell, Inc.) and rapidly rinsed further with $2.5 \mathrm{ml}$ of the ice-cold $250 \mathrm{~mm} \mathrm{NaCl} / 1 \mathrm{~mm}$ Tris- $\mathrm{HCl}$ buffer. $\mathrm{Na}^{+}$-dependent glucose uptake or phlorizin-binding activity was calculated by subtracting the amount of substrate in the presence of $\mathrm{K}^{+}$from that in the presence of $\mathrm{Na}^{+}$. These assays were done within $9 \mathrm{~h}$ after the rats had been sacrificed. 
Scanning electron microscopy. A small area of jejunal tissue next to the everted jejunal segment used for $\triangle \mathrm{PD}$ measurements was quickly flushed with $0.1 \mathrm{M}$ sodium phosphate buffer ( $\mathrm{pH} 7.2$ ), slit open lengthwisely on filter paper, and fixed in $2.5 \%$ glutaraldehyde in $0.1 \mathrm{~m}$ sodium phosphate buffer $(\mathrm{pH}$ 7.2) for $2 \mathrm{~h}$. After fixation, the tissues were rinsed with the phosphate buffer and placed in the same buffer containing $1 \%$ osmium tetroxide for $2 \mathrm{~h}$. The tissues were dehydrated through a graded series of ethanol and isoamylacetate, carefully fractured in liquid nitrogen, and dried in a critical point dryer (HCP-1, Hitachi) using $\mathrm{CO}_{2}$ as the transitional fluid. All samples were coated in a gold vapor coater (Hummer II, Technics) and examined by scanning electron microscopy (S-800, Hitachi). From the scanning electron micrographs, thickness of the jejunal wall, height of villi and crypts, height and surface area of epithelial cells, number of microvilli per square micrometer, and length and diameter of microvilli were measured. For these estimations from the scanning electron micrographs, the jejunal villous surfaces examined were limited to the area on the middle part of the villi.

Disaccharidase assay and protein determination. After the measurement of $\triangle \mathrm{PD}$ evoked by sugars, jejunal mucosa from each everted segment was homogenized with 9 vol of the standard solution $\left(\mathrm{pH} \mathrm{7.4)}\right.$ and stored at $-20^{\circ} \mathrm{C}$ until used. An aliquot of the homogenate was used for the assay of maltase and sucrase activities. An aliquot of brush border membrane vesicles was used for the assay of sucrase activity. Disaccharidase activities were determined by the method of Dahlqvist [13]. Protein concentration was determined by the method of Lowry et al. [17] using bovine serum albumin as a standard.

Chemicals. Glucose and sucrose were obtained from Wako Pure Chemical Industries Ltd. Maltose was provided by Hayashibara Co., Ltd. Phlorizin was purchased from Sigma Chemical Co. Glucose oxidase and peroxidase were from Worthington Biochem. Co., glutaraldehyde was from TAAB Laboratories, and osmium tetroxide, from E. Merck. D- $\left[{ }^{3} \mathrm{H}\right]$ Glucose and $\left[{ }^{3} \mathrm{H}\right]$ phlorizin were purchased from New England Nuclear Corp. Other reagents were all analytical grade chemicals.

\section{RESULTS}

Effect of fasting and refeeding on body weight, intestinal weight, and blood glucose. As shown in Table 1, the most marked weight loss occurred during the first day of fasting, the rats losing about $30 \mathrm{~g}$ in $24 \mathrm{~h}$. Similarly the weight gain was the most marked after the first day of refeeding. Adult male rats lost $22 \%$ of their initial body weight during the 5 days of fasting. On refeeding, animals recovered weight losses up to the initial level within 3 days. Their food intake was almost the same amount, about $30 \mathrm{~g} /$ day/rat, during the experiment. The weight of mucosal scrapings from the jejunum did not change during the first $24 \mathrm{~h}$ fasting, but did so after 3 days (Table 1).

Blood glucose concentration decreased from $108 \mathrm{mg} / \mathrm{dl}$ to $71 \mathrm{mg} / \mathrm{dl}$ after 1 day 


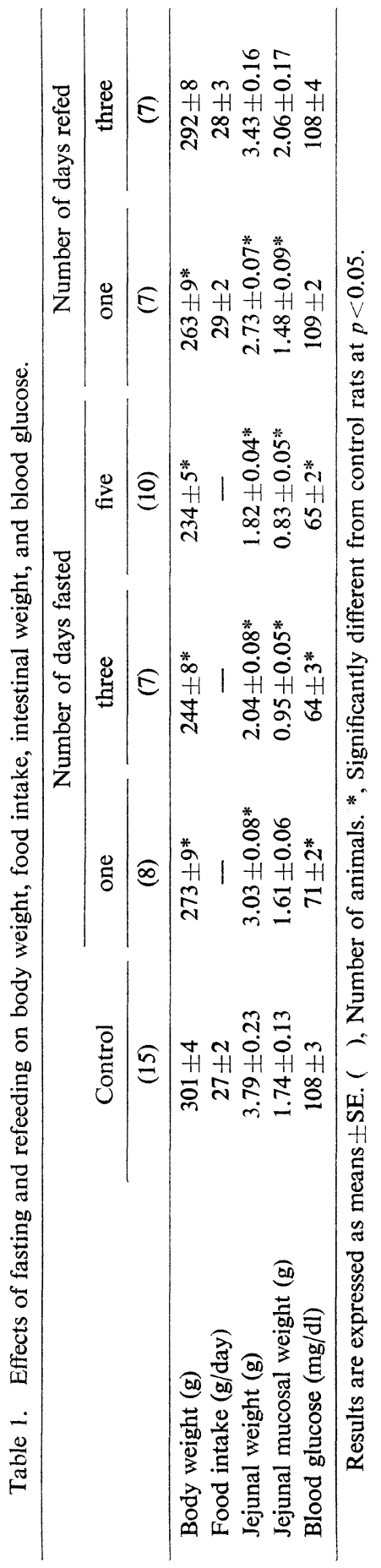

Vol. 1, No. 1, 1986 
of fasting, maintained the same level during fasting, and then increased to the control level after refeeding.

Effect of fasting and refeeding of sugar-evoked transmural potential differences and disaccharidase activities in rat jejunum. The changes in sugar-evoked potential

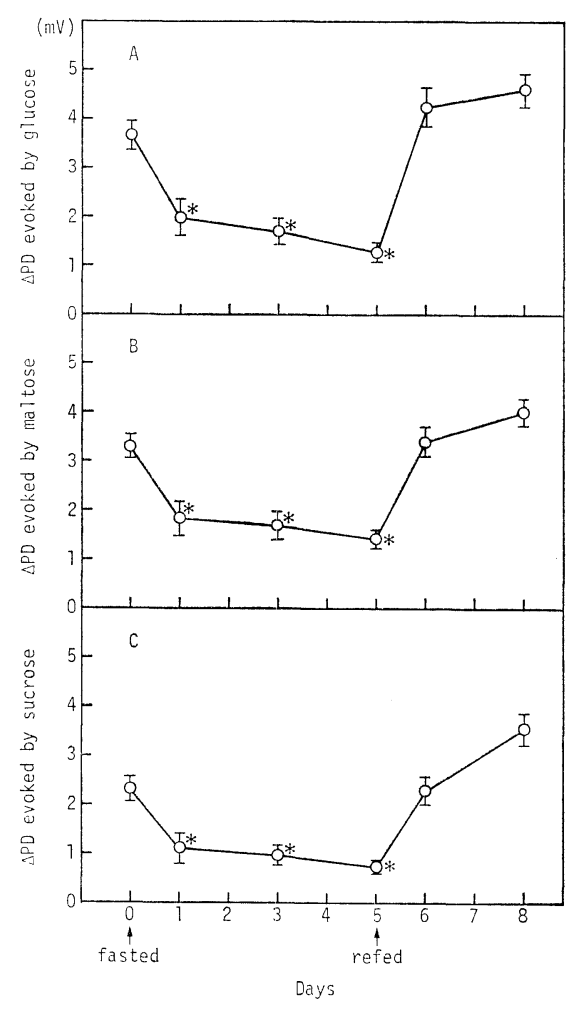

Fig. 1

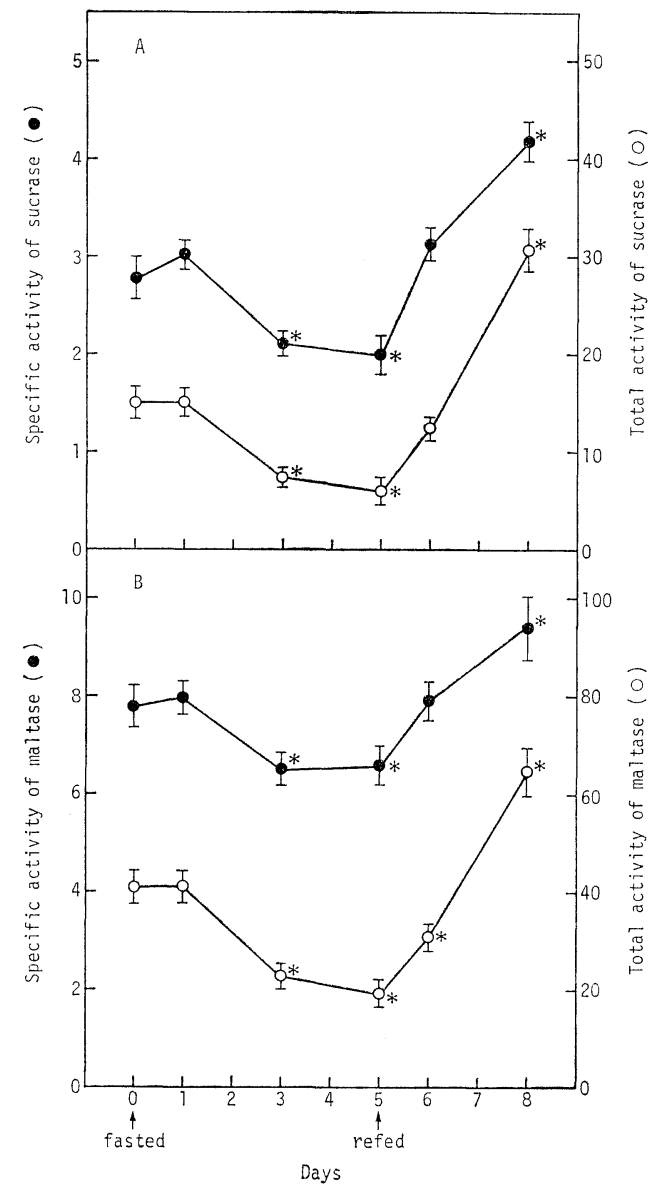

Fig. 2

Fig. 1. Transmural potential difference evoked by glucose, maltose or sucrose in the rat jejunum during fasting and refeeding. Results are expressed as means $\pm S E$ of 7-15 animals. $\triangle \mathrm{PD}$ was measured at the concentration of $20 \mathrm{~mm}$ glucose (A), $10 \mathrm{~mm}$ maltose (B), or 40 $\mathrm{mm}$ sucrose (C) in the standard solution containing $50 \mathrm{~mm} \mathrm{Na} \mathrm{Na}_{4}(\mathrm{pH} 7.4)$. *, Significantly different from control at $p<0.05$.

Fig. 2. Sucrase and maltase activities in the rat jejunum during fasting and refeeding. Results are expressed as means \pm SE of 7-15 animals. Enzyme activities were measured in the homogenate of jejunal mucosa after the measurement of $\triangle \mathrm{PD}$. Substrate concentration were $40 \mathrm{~mm}$ sucrose (A) or $10 \mathrm{~mm}$ maltose (B) in the standard solution (pH 7.4). *, Significantly different from control at $p<0.05$. Specific activity, $\mu$ mol substrate $/ \mathrm{mg}$ protein $/ \mathrm{h}$. Total activity, $\mu \mathrm{mol}$ substrate $/ \mathrm{cm}$-gut $/ \mathrm{h}$. 
difference $(\triangle \mathrm{PD})$, when sugars were added to the mucosal side, are presented as increments in mucosal negativity in everted jejunum of fasted and refed rats (Fig. 1). On the first day of fasting, the jejunal $\triangle \mathrm{PD}$ evoked by glucose was significantly decreased from that of the control group. During fasting, the $\triangle \mathrm{PD}$ evoked by glucose showed a progressive small decrease, but it was not significant. After refeeding was started, the $\triangle \mathrm{PD}$ evoked by glucose increased to the level of control rats within $24 \mathrm{~h}$. The $\triangle \mathrm{PD}$ evoked by maltose was almost the same as that by glucose, while the $\triangle \mathrm{PD}$ evoked by sucrose was lower than that by glucose. All three sugars elicited similar $\triangle \mathrm{PD}$ patterns during fasting and refeeding (Fig. 1).

After the measurement of potential difference, maltase and sucrase activities were assayed in the mucosal homogenate of jejunal everted intestine. The time course of the changes in specific (per unit of protein) activities of maltase and sucrase during 5 days of fasting and a successive refeeding for 3 days is shown in Fig. 2. A significant decrease in sucrase specific activity appeared on the third day of fasting. It decreased to three-fourths of the control level and did not change further during the period of starvation. Refeeding of the laboratory chow increased sucrase activity very rapidly to that seen in the control group within $24 \mathrm{~h}$ and even above that level by 3 days of refeeding. Similar trends were observed in maltase activity, but the effect of fasting on maltase activity was not so big as that on sucrase activity. These changes in disaccharidase activities were magnified when expressed as total activity per $1 \mathrm{~cm}$ of jejunal segment (Fig. 2).

Glucose uptake and phlorizin-binding activity to the jejunal brush border membrane vesicles of fasted and refed rats. In order to determine whether the changes in $\triangle \mathrm{PD}$ evoked by glucose were accompanied by changes in the glucose transporter, $\mathrm{Na}^{+}$-dependent glucose uptake and $\mathrm{Na}^{+}$-dependent phlorizin-binding activity to the brush border membrane vesicles of fasted and refed rats were measured. The specific activity of sucrase in brush border membrane vesicles was increased about 15 -fold compared with that of the mucosal homogenate, and recovery of the activity

Table 2. Effect of fasting and refeeding on sucrase activity, glucose uptake, and phlorizinbinding activity in brush border membrane vesicles from rat jejunum.

\begin{tabular}{|c|c|c|c|c|}
\hline & \multirow[b]{3}{*}{ Control } & \multicolumn{3}{|c|}{ Number of days } \\
\hline & & \multicolumn{2}{|c|}{ fasted } & \multirow{2}{*}{$\begin{array}{l}\text { refed } \\
\text { three }\end{array}$} \\
\hline & & one & five & \\
\hline & (7) & (5) & (7) & (5) \\
\hline $\begin{array}{l}\text { Sucrase activity } \\
\quad(\mu \mathrm{mol} \text { substrate/mg protein } / \mathrm{h})\end{array}$ & $69.8 \pm 2.4$ & $77.7 \pm 5.6$ & $39.4 \pm 4.5^{*}$ & $94.7 \pm 9.6^{*}$ \\
\hline $\begin{array}{l}\text { Glucose uptake } \\
(\mathrm{nmol} / \mathrm{mg} \text { protein } / 15 \mathrm{~s})\end{array}$ & $1.05 \pm 0.15$ & $1.02 \pm 0.14$ & $1.20 \pm 0.20$ & $1.31 \pm 0.17$ \\
\hline $\begin{array}{l}\text { Phlorizin binding } \\
\text { (pmol/mg protein/15 s) }\end{array}$ & $57.3 \pm 4.0$ & $60.1 \pm 6.0$ & $56.6 \pm 5.3$ & $59.8 \pm 7.2$ \\
\hline
\end{tabular}

Results are expressed as means \pm SE. ( ), Number of animals. *, Significantly different from control rats at $p<0.01$.

Vol. 1, No. 1, 1986 
Table 3. Morphological parameters of jejunal villi and microvilli in control and 5 day-fasted rats.

\begin{tabular}{|c|c|c|c|}
\hline & & Control & 5 days-fasted \\
\hline Thickness of intestinal wall $(\mu \mathrm{m})$ & (10) & $554 \pm 20$ & $418 \pm 21 *$ \\
\hline Height of villi $(\mu \mathrm{m})$ & $(10)$ & $374 \pm 12$ & $244 \pm 12 *$ \\
\hline Height of crypt $(\mu \mathrm{m})$ & (10) & $97 \pm 3$ & $102 \pm 5$ \\
\hline Height of epithelial cells $(\mu \mathrm{m})$ & $(50)$ & $34.6 \pm 0.9$ & $23.5 \pm 0.8^{*}$ \\
\hline $\begin{array}{l}\text { Surface area of epithelial cell } \\
\left(\mu \mathrm{m}^{2} / \text { epithelial cell }\right)\end{array}$ & $(50)$ & $17.5 \pm 0.01$ & $9.17 \pm 0.02 *$ \\
\hline $\begin{array}{l}\text { Number of microvilli/ } \mu \mathrm{m}^{2} \text { of epithelial } \\
\text { cell surface }\end{array}$ & (21) & $57 \pm 4$ & $83 \pm 6^{*}$ \\
\hline Length of microvilli $(\mu \mathrm{m})$ & $(63)$ & $0.83 \pm 0.01$ & $1.12 \pm 0.02 *$ \\
\hline Diameter of microvilli $(\mu \mathrm{m})$ & (63) & $0.132 \pm 0.001$ & $0.098 \pm 0.001 *$ \\
\hline
\end{tabular}

Results are expressed as means \pm SE. ( ), Number of measured sites. *, Significantly different from control rats at $p<0.01$.

was about $40 \%$ in all groups. As shown in Table 2, sucrase specific activity in the jejunal brush border membrane vesicles did not decrease compared with that in the control group after 1 day of fasting, but dropped significantly after 5 days of fasting. Then it increased considerably above the control level after 3 successive days of refeeding, in good agreement with the results for the jejunal homogenate.

$\mathrm{Na}^{+}$-dependent glucose uptake by brush border membrane vesicles did not change in any of the groups. Similarly phlorizin-binding activities remained the same in control, fasted, and refed rats (Table 2).

Changes in morphological parameters of villi and microvilli in the fasted rat jejunum. Five day-fasted jejunum which showed the most significant decreases in $\triangle \mathrm{PDs}$ evoked by sugars and disaccharidase activities, was further examined by scanning electron microscopy, and the results were compared with those of the control jejunum.

The thickness of the jejunum was decreased in five day-fasted rats compared with that in control rats, in good agreement with the reduction in mucosal weight. The decrease in jejunal wall thickness was mainly dependent on the decrease in villous height rather than in crypt height (Fig. 3-1, 2, Table 3). Enterocyte height in fasted rats was a little shorter than that in control rats. Moreover, the surface area per epithelial cell was significantly decreased by fasting (Fig. 3-3, 4) with a change of microvillous shape (Fig. 4, Table 3). The length of microvilli was increased by fasting, whereas their diameter was rather decreased (Fig. 4, Table 3). On the assumption that microvilli can be geometrically represented as dome-capped cylinders, the surface areas of microvilli were determined from these measurements, as suggested by Anderson and Taylor [18]. As a result, the surface area of one microvillus was estimated as $0.346 \mu \mathrm{m}^{2}$ for control animals and $0.345 \mu \mathrm{m}^{2}$ for fasted animals. On the other hand, the number of microvilli per square micrometer of villous surface was greater in fasted animals than in control ones, though the number of microvilli possessed by one epithelial cell was much less in fasted than in control animals due to a significant reduction in epithelial cell surface area by 


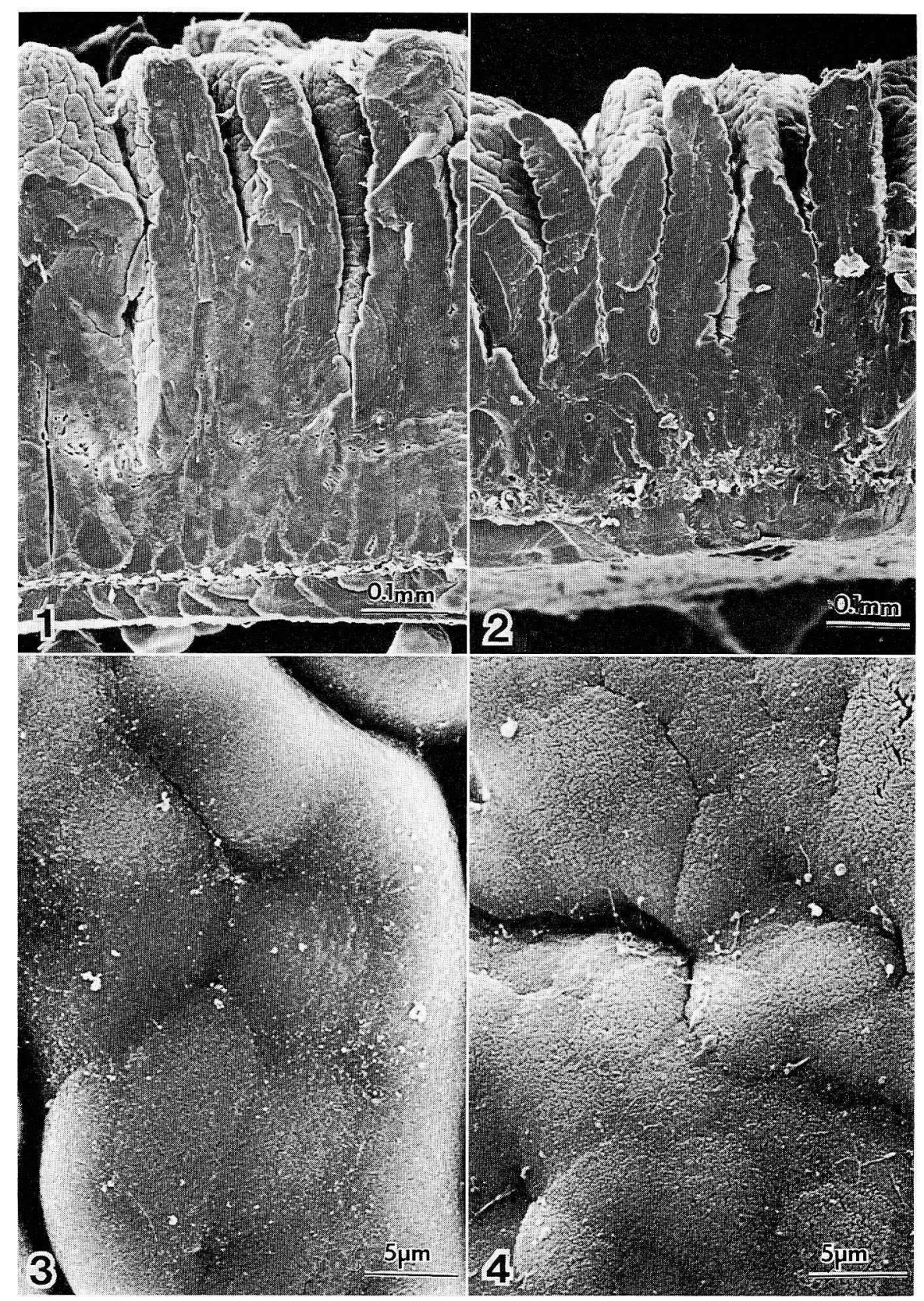

Fig. 3. Scanning electron micrographs of jejunal villi $(1,2)$ and surface of jejunal epithelial cells $(3,4)$ in control and 5 day-fasted rats. 1 and 3 are from control animals, and 2 and 4 , from fasted ones. Magnification $\times 130(1$ and 2$), \times 3,000(3$ and 4$)$. 


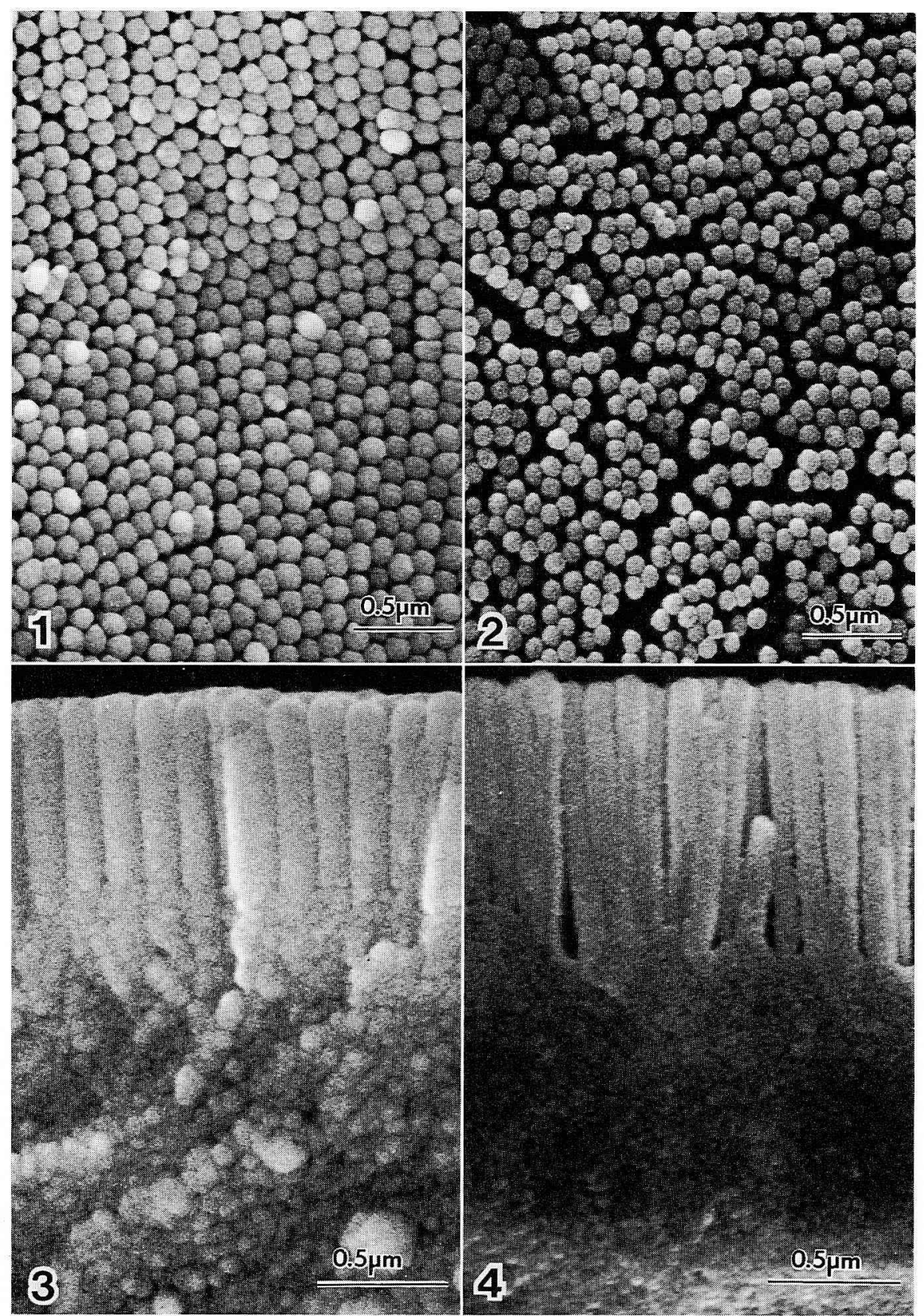

Fig. 4. Scanning electron micrographs of jejunal microvilli in control and 5 day-fasted rats. 1 and 3 are from control animals, and 2 and 4, from fasted ones. 1 and 2 show the luminal surface of microvilli. 3 and 4 show longitudinal views of microvilli. Magnification $\times 30,000$ ( 1 and 2$), \times 40,000$ ( 3 and 4 ). 
fasting. Therefore, the entire surface area of microvilli per epithelial cell seemed to be significantly decreased by fasting.

\section{DISCUSSION}

In the present study, the effects of fasting and refeeding on the adaptive changes in sugar absorption were observed in rat small intestine.

In good agreement with a previous report that fasting causes a decrease in intestinal weight [19], we found that the mucosal weight decreased after 3 days of fasting and increased very quickly after refeeding. The response of refeeding seemed to be more rapid than that of fasting. Fasting also reduced the height of the jejunal villi and the surface area per epithelial cell with a change in microvillous shape. It is reported that mucosal cell proliferation in crypts is greatly influenced by fasting in rats. Number of mucosal cells, DNA content, and mucosal uptake of $\left[{ }^{3} \mathrm{H}\right]$ thymidine were shown to be reduced as was the migration rate of cells up to the villous tip [19-21]. Therefore, the entire surface area of the jejunal villus was much smaller in fasted than in control animals.

Total deprivation of diet significantly decreased maltase and sucrase activities in the jejunal mucosa. A highly significant decrease in both specific and total activities of the enzymes occurred after $24 \mathrm{~h}$ of fasting. Refeeding the diet increased maltase and sucrase activities very rapidly. These results confirmed previous studies $[1,2]$. On the other hand, the transmural potential difference $(\Delta \mathrm{PD})$, which is induced by a net mucosal-serosal flux of glucose accompanied with that of $\mathrm{Na}^{+}$, was significantly decreased in fasted animals within $24 \mathrm{~h}$, despite no change in disaccharidase activity. $\triangle$ PDs evoked by maltose and sucrose, which are supposed to be induced by glucose released from the hydrolysis of these disaccharides, were also changed during fasting and refeeding in the same manner as the glucose-evoked $\triangle \mathrm{PD}$. Debnam and Levin [9] reported that the decrease in $\triangle \mathrm{PD}$ evoked by glucose after 3 days of fasting correlated with a decrease in enterocyte number. However, it is interesting to note the difference between $\triangle \mathrm{PD}$ evoked by disaccharides and disaccharidase activity on the first day of fasting. There appears to be no direct correlation between digestion and absorption, when disaccharidase activity is relatively high. Murray and Wild [22] reported that $\mathrm{Na}^{+}-\mathrm{K}^{+}-$ATPase activity of rat jejunum decreased within $17 \mathrm{~h}$ after the beginning of fasting. Therefore, a decrease in the electrochemical gradient generated by $\mathrm{Na}^{+}$in jejunal tissue could contribute to a decrease in $\mathrm{Na}^{+}$-coupled transport.

Glucose absorption in the small intestine occurs by a carrier-mediated transport mechanism in the brush border membrane of epithelial cells [12,15]. In order to determine whether decreased or increased $\triangle \mathrm{PDs}$ are due to intrinsic alterations in the plasma membrane properties of the epithelial cells, we measured glucose uptake by and phlorizin binding to the $\mathrm{Na}^{+}$-glucose cotransporter of brush border membrane vesicles. In spite of a significant change in sucrase activity, both the capacity of glucose uptake and the phlorizin-binding activity did not change during

Vol. 1, No. 1, 1986 
fasting and refeeding. These results suggest that the number of glucose transporters in the brush border membrane is not affected by fasting when expressed as a function of the membrane unit. However, the total number of transporters could be decreased because of the reduction in the amount of brush border membrane which occurs during fasting. It is reported that a starved animal shows a decreased $V_{\max }$ without any change in $K_{\mathrm{m}}$ for glucose transport and luminal nutrients maintained the capacity of glucose absorption [23]. Consideration of adaptive changes in glucose absorption is needed to interprete the changes in the surface area of intestine or in the amount of brush border membrane, as well as changes in specific activity. Furthermore, it is also important to consider the metabolism of epithelial cells. For example, it is known that the effect of fasting on active uptake of monosaccharides seems to be largely due to the withdrawal of dietary carbohydrate [24] and that glucose transport is induced by an increase in blood glucose in diabetic rat intestine [25]. In our study the changes in blood glucose paralleled the $\triangle \mathrm{PD}$ evoked by glucose during fasting and refeeding.

In conclusion, our results have shown that the absorption of sugar in the small intestine decreases or increases by fasting or refeeding very rapidly, although further studies will be required to unravel the mechanism of the adaptive changes in brush border membranes and the metabolism of enterocytes in response to luminal factors.

\section{REFERENCES}

1. Deren, J.J., Broitman, S.A., and Zamcheck, N. (1967): Effect of diet upon intestinal disaccharidases and disaccharide absorption. J. Clin. Invest., 46, 186-195.

2. Yamada, K., Goda, T., Bustamante, S., and Koldovsky, O. (1983): Different effect of starvation on activity of sucrase and lactase in rat jejunoileum. Am. J. Physiol., 244, G449-G455.

3. Cameron, I.L., Pavlat, W.A., and Urban, E. (1974): Adaptive response to total intravenous feeding. J. Surg. Res., 17, 45-52.

4. McCarthy, D.M., and Kim, Y.S. (1973): Changes in sucrase, enterokinase and peptide hydrolase after intestinal resection. The association of cellular hyperplasia and adaptation. J. Clin. Invest., 52, 942-951.

5. Caspary, W.F. (1973): Effect of insulin and experimental diabetes mellitus on the digestiveabsorptive function of the small intestine. Digestion, 9, 248-263.

6. Goda, T., Hosoya, N., and Moriuchi, S. (1983): Changes of the activity and content of sucraseisomaltase complex in the intestinal mucosa during the development of streptozotocin-induced diabetes in rats. J. Nutr. Sci. Vitaminol., 29, 571-578.

7. Steiner, M., and Gray, S.J. (1969): Effect of starvation in intestinal amino acid absorption. Am. J. Physiol., 217, 747-752.

8. Newely, H., Sanford, P.A., and Smyth, D.H. (1970): Effects of fasting on intestinal transfer of sugars and amino acids in vitro. J. Physiol., 208, 705-724.

9. Debnam, E.S., and Levin, R.J. (1975): Effects of fasting and semistarvation on the kinetics of active and passive sugar absorption across the small intestine in vivo. J. Physiol., 252, 681-700.

10. Schedl, H.P., Burston, D., Taylor, E., and Matthews, D.M. (1979): Kinetics of uptake of an amino acid and a dipeptide into hamster jejunum and ileum. The effect of semistarvation and starvation. Clin. Sci., 56, 487-492. 
11. Lyon, I., and Crane, R.K. (1966): Studies on transmural potentials in vitro in relation to intestinal absorption. Biochim. Biophys. Acta, 112, 278-291.

12. Toggenburger, G., Kessler, M., Rothstein, A., Semenza, G., and Tannenbaum, C. (1978): Similarity in effects of $\mathrm{Na}^{+}$gradients and membrare potentials on D-glucose transport by, and phlorizin binding to, vesicles derived from brush borders of rabbit intestinal mucosal cells. J. Membr. Biol., 40, 269-290.

13. Dahlqvist, A. (1964): Method for assay of intestinal disaccharidases. Anal. Biochem., 7, 18-25.

14. Igarashi, Y., Saito, Y., Himukai, M., and Hoshi, T. (1976): Interaction of disaccharidedependent electrical potential difference in the small intestine. Jpn. J. Physiol., 26, 79-92.

15. Hopfer, U., Nelson, K., Perrotto, J., and Isselbacher, K. (1973): Glucose transport in isolated brush border membrane from rat small intestine. J. Biol. Chem., 248, 25-32.

16. Klip, A., Grinstein, S., and Semenza, G. (1979): Partial purification of the sugar carrier of intestinal brush border membranes. Enrichment of the phlorizin binding component by selective extractions. J. Membr. Biol., 51, 47-73.

17. Lowry, O.H., Rosebrough, N.J., Farr, A.L., and Randall, R.J. (1951): Protein measurement with the Folin phenol reagent. J. Biol. Chem., 193, 265-275.

18. Anderson, J.H., and Taylor, A.B. (1973): Scanning and transmission electron microscopic studies of jejunal microvilli of the rat, hamster and dog. J. Morphol., 141, 281-292.

19. Steiner, M., Bourges, H.R., Freedman, L.S., and Gray, S.J. (1968): Effect of starvation on the tissue composition of the small intestine in the rat. Am. J. Physiol., 215, 75-77.

20. Altmann, G.G. (1972): Influence of starvation and refeeding on mucosal size and epithelial renewal in the rat small intestine. Am. J. Anat., 133, 391-400.

21. Hagemann, R.F., and Stragand, J.J. (1977): Fasting and refeeding; cell kinetic response of jejunum, ileum and colon. Cell Tissue Kinet., 10, 3-14.

22. Murray, D., and Wild, G.E. (1979): Effect of fasting on Na-K ATPase activity in rat small intestinal mucosa. Can. J. Physiol. Pharmacol., 58, 643-649.

23. Kolter, D.P., Levine, G.M., and Shiau, Y.F. (1980): Effects of nutrients, endogenous secretions, and fasting on in vitro glucose uptake. Am. J. Physiol., 238, G219-G227.

24. Diamond, J.M., and Karasov, W.H. (1984): Effect of dietary carbohydrate on monosaccharide uptake by mouse small intestine in vitro. J. Physiol., 349, 419-440.

25. Csasky, T.Z., and Fischer, E. (1981): Intestinal sugar transport in experimental diabetes. Diabetes, 30, 568-574. 